University of Nebraska - Lincoln

DigitalCommons@University of Nebraska - Lincoln

Summer 2005

\title{
Patrilateral Bias among a Traditionally Egalitarian People: Ju/hoansi Naming Practice
}

\author{
Patricia Draper \\ University of Nebraska - Lincoln, pdraper1@unl.edu \\ Christine Haney \\ University of Nebraska-Lincoln, chaney3@unl.edu
}

Follow this and additional works at: https://digitalcommons.unl.edu/anthropologyfacpub

Part of the Anthropology Commons

Draper, Patricia and Haney, Christine, "Patrilateral Bias among a Traditionally Egalitarian People: Ju/'hoansi Naming Practice" (2005). Anthropology Faculty Publications. 36.

https://digitalcommons.unl.edu/anthropologyfacpub/36

This Article is brought to you for free and open access by the Anthropology, Department of at DigitalCommons@University of Nebraska - Lincoln. It has been accepted for inclusion in Anthropology Faculty Publications by an authorized administrator of DigitalCommons@University of Nebraska - Lincoln. 


\section{PATRILATERAL BIAS AMONG A TRADITIONALLY EGALITARIAN PEOPLE: JU/'HOANSI NAMING PRACTICE}

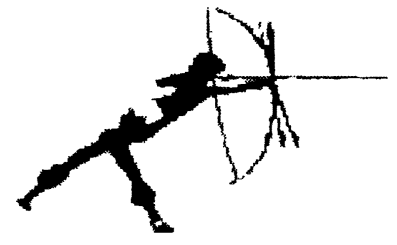

\author{
Patricia Draper \\ Christine Haney \\ University of Nebraska, Lincoln
}

The Ju/'hoansi (!Kung) of Namibia and Botswana are unusual for the strong norm to name children exclusively for kin and primarily for grandparents. Naming carries important significance by linking the two namesakes and because names are a basis for extending fictive kin links. In the 1950s Lorna Marshall reported that the father has the right to name children and that he "invariably" named them for the paternal grandparents, although having the option of naming children born later for his wife's parents. The authors used a large database of genealogical information that was collected nearly concurrently with Marshall's report to test the strength of the naming rule and found that approximately 70 per cent of men name the first-born son or daughter for their own parent of the child's gender. The degree of compliance is of interest because it falls short of 100 per cent. However, analysis of the naming patterns reveals a strong patrilateral bias in naming for the paternal rather than the maternal grandparents. This type of gender and unilateral bias is not normally reported for Ju/'hoansi, who are otherwise described as gender egalitarian and bilateral in most customary practices. (San names, Cultural consensus, Gender roles, Names, Kinship, Quantification)

This article is about egalitarianism, bilateral kinship, and balanced gender roles among the Ju/'hoansi (also known as !Kung or San) of Botswana, and uses data collected on the Ju/'hoansi of Botswana and Namibia during the 1950s and 1960s, when major changes in society had not yet taken place. Bilateral asymmetry and inegalitarian gender relations were already present in the culture then, but had not been documented empirically. This appears in the practice of naming children, an entitlement that belonged to men alone, and to the fact that the custom heavily favored naming children for the father's parents and the relative neglect of naming children for the wife's parents.

The details of the naming custom were described by Lorna Marshall (1957) for Ju/'hoansi (singular, Ju) living in the Nyae Nyae region of South West Africa (now Namibia) and have been reported for other Ju (Lee 1979). However, the fact that the naming rules contradicted the bilateralism and gender symmetry found elsewhere in the culture has not been previously singled out for attention. This essay concerns a group contemporaneous with Marshall's population who were their near neighbors on the east side of the Namibian border with Botswana. These are the ethnographically well known Ju/'hoansi of the Dobe area, well known in the anthropological literature (Howell 2000b; Lee 1979). 


\section{THE NAMING CUSTOM}

In the mid-20th Century, authority to name a child was granted solely to the child's father (Marshall 1976:223-25). Marshall reports that he "invariably" named the first male and first female child for his parents (the paternal grandparents). The rule for naming other children was not specific, except that the child be given the name of a relative who was at least one generation older than the child. That relative might be a maternal grandparent or other kin of the father or mother. Gaining a namesake was an honor not everyone received. In particular, not all grandparents had a grandchild namesake, particularly those older people who only had daughters or whose sons had not survived to reproduce.

The choice of namesake was considered a serious matter because people believed the child, known as !uma, (lit. the small name) and his or her namesake, !un! $a$, (lit. the big or old name) were symbolically as well as socially joined. $\mathrm{Ju} /$ 'hoansi thought that the child namesake embodied or carried on the "essence" of the old name. The effects of being joined in a namesake dyad were not limited to the older-young pair, although it created a special tie between them. Others, people who were relatives of the old name, incorporated the small name into their kin terminological system "as if" the child were the actual old name, albeit a younger version. In this way, the child, known as the small name, acquired a substantial, ready-made social network that could become important to the child later in his or her life, as they made themselves known to the child on behalf of their previously existing relationships with the old name.

The custom of naming a child for the father's parents persisted regardless of whether the old name was already dead when given the namesake, or whether he or she died at some later time (Haney 2004). Because of the close identification of the small name with the old name, any time the relatives of the old name addressed or referred to the small name (using the kin terminology derived from their relationship to the old name), they invoked the memory of the deceased. Further, the child and all other people had to learn the basis of this individualized kin appellation in order to understand why people used certain kin terms for certain others. Such a custom may have operated as a mnemonic for genealogical relationships, since many people in this society were terminologically classified with their old names by certain other people. For other people to understand why a given child (or adult) small name was spoken to by a given kin term by another person (who could not have been related in that way to the small name) would require those others to know who the old name was and how the speaker was related to the old name. 
The inventory of names was gender specific and a subset of them tended to repeat in alternating generations within a family. A parent and a child could not have the same name, but it was expected that grandparents who had sons would share the name of at least one of their grandchildren (Marshall 1976:224). As a consequence of naming children for grandparents and for specific other senior kin, there was a limited repertoire of male and female names ${ }^{1}$ among the Ju of a particular region (Lee 1986). Last, Ju/'hoansi retain their names throughout life. Rare instances of name changes have been reported, sometimes for infants but also for adults, usually to remove the obstacle of "name incest" which would occur if a person were to marry someone with the same name as his or her nuclear family kin.

The focus on Ju/'hoan naming for this article is the grandparent-grandchild dyad. Not considered are the choices men made when they named children for non-grandparental kin. The two contributions made here to the literature on the $\mathrm{Ju} /$ 'hoansi are, first, drawing attention to the naming custom as it constitutes a contradiction to the more general egalitarianism that ethnographers have attributed to this society; and, second, reporting quantitatively on the naming custom as it was practiced in the 1960s and describing the degree of gender and patrilateral bias that existed.

\section{ETHNOGRAPHIC BACKGROUND}

Past studies of the Ju/'hoansi San peoples of Southern Africa emphasize the egalitarian characteristics of the society. This culture of egalitarianism applied to male-female relations as well as to relations among adult males (Lee 1969, 1979; Marshall 1961; Wiessner 1982, 2002). Ju made decisions by consensus and no one had the authority to coerce another person. Having a bilateral kinship system, there was no distinction among kin of the father versus the mother in terms of inheritance or ritual precedence. Residence rules were bilocal, following a period of uxorilocality during bride service (Marshall 1959). In former times, when Ju/'hoansi lived mostly by foraging, economic equality was more or less assured by the requirement of mobility which discouraged accumulation of all but necessities. Both men and women had separate entitlements to territories ( $n$ !oresi, sing., $n$ !ore) that were inherited from parents and passed on to sons and daughters. This meant that access to resources was approximately equal for men and women, although men and women specialized separately in hunting and gathering. Frequent residential changes and bilocal residence ensured that women were not isolated from the social support of their own kin, as happens in societies with a patrilocal residence rule that allows brothers to stay with their father's kin and to import wives from other communities (Draper 1975, 1992; Lee 1974). 
In the five decades since the early writings by Marshall, and later by Lee and other members of the Harvard Kalahari Expedition who studied Ju/'hoan populations in Botswana, many secular changes have occurred, among them practices that have reduced some aspects of egalitarianism (Yellen 1990). For example, economic disparities now occur among Ju/'hoansi who live in settled villages and gender roles are no longer as balanced as in former times. These transformations are too numerous to review here; published descriptions are available (Becker 2003; Hitchcock, Johnson, and Haney 2005; Lee and Hitchcock 2001; Lee and Hurlich 1982; Saugestad 2003; Wiessner 2004). For a contemporary portrayal of gender roles among San (including Ju/'hoansi) of eastern Namibia, see Sylvain (In press and 2004).

The factors that contribute to the loss of egalitarian customs are common to tribal peoples who have been incorporated into state polities. External government officials, with whom Ju must increasingly interact, recognize men rather than women as acceptable intermediaries. Boys and young men have been better able to take advantage of educational and wage earning opportunities (Hays 2003). However, even among men there were differences of aptitude and willingness to remain in school or to acquire new skills in employment. In modern times these experiences translated into differences of prestige and income that would not have been possible when people lived as foragers. As $\mathrm{Ju} /$ 'hoansi have settled into permanent villages, the former economic and social patterning of gender roles has broken down; alcohol abuse has become common, and has led to public and private violence in which women are heavily targeted (Ritchie 1986). The ethnographic present for this study, however, is the late 1960s.

\section{METHODS AND MATERIALS}

The data for the analysis of naming practices come from several sources made available by members of the original Harvard Kalahari Research Project (HKRP). ${ }^{2}$ In his dissertation research of the mid 1960s, Richard Lee gave each living Ju he met a unique identifying number and collected genealogical data of varying detail on that person (Lee 1965). Nancy Howell continued with demographic research ${ }^{3}$ on the same base population (Howell 2000a). Patricia Draper, also a member of HKRP, added to the numbered list and to the genealogical information. Later, she incorporated these disparate sources of information on individuals into a relational data base format which made it possible to look for patterns in the names and name-sharing between grandparents and grandchildren. The second author, Haney, used these data in her Master's Thesis, portions of which are the basis of the present study (Haney 2004). 
The original data files from the HKRP included records on more than 800 individuals, many of whom were related as grandparents, siblings, parents, children, grandchildren, and great-grandchildren. ${ }^{4}$ We restricted that group severely, limiting our final sample to only certain men, women, and children on whom there was full information. ${ }^{5}$ We had to drop some individuals, such as infants who had died before being named, children whose fathers were non-Ju and who, therefore, would not be expected to name a child according to the traditional rule. We also dropped men and women for whom information on their parents, the grandparents of their children, were missing.

The study was based on the individuals listed in Tables 1,2 , and 3 . The reader should remember that each child can have two parents and four grandparents. For the purposes of the analysis here, we were concerned only with whether a child was or was not named for one of the four grandparents, and the percentages of men and women who had a child named for one of the child's four grandparents. Typically, only one child of a man is named for a given grandparent. An exception occurs, albeit rarely, when a man renames a second child for the same person because the first one died. Renaming, though rare, is more often done on behalf of paternal grandparents (Haney 2004).

Our final sample was composed of 72 men and 103 women and the parents of the men and women (grandparents). We had full information on 118 paternal grandparents calculated through $72 \mathrm{men}$, and complete information on 179 maternal grandparents calculated through 103 women (see Tables 2 and 3). The children of the 72 men numbered 297, including 152 boys and 145 girls. The 103 women had 448 children, composed of 223 boys and 225 girls. These people constituted the three generational sets for whom we had reliable information on the names of each person in the set. Keep in mind the reticulated nature of these individual data points. Some but not all grandparents are connected to both male and female adult children and to male and female grandchildren. Our analyses, however, are based on an approach that considers each child of a given man or woman as a "naming event." A man can name each of his children in five different ways: for the paternal grandfather; for the paternal grandmother; for the maternal grandfather; for the maternal grandmother; or none of the above.

Our data contained details such as the birth orders of the children and whether their grandparents were alive or dead at the time of data collection. Since we were interested in whether men named for one of the four grandparents, we retained grandparents and grandchildren (regardless of whether they were living or dead at the time of original data collection), provided we knew the names of all concerned. We retained cases for which we could trace the connection between a child and either mother or father, and therefore were able to determine whether a given child had been given the name of its same-sexed paternal or maternal grandparent. See Tables 2 and 3 for exact numbers of boys 
Table 1

Number and Sex of Children Born to Study Sample

\begin{tabular}{|c|c|c|}
\hline Father & Boy & Girl \\
\hline 72 & 152 & \\
\hline 68 & & 145 \\
\hline Mother & Boy & Girl \\
\hline 103 & 223 & \\
\hline 103 & & 225 \\
\hline
\end{tabular}

Table 2

Male, Three Generational Linkages

\begin{tabular}{|c|c|c|}
\hline Father & Boy & $\begin{array}{c}\text { Paternal } \\
\text { Grandfather }\end{array}$ \\
\hline 72 & 152 & 61 \\
\hline Mother & Boy & $\begin{array}{c}\text { Maternal } \\
\text { Grandfather }\end{array}$ \\
\hline 103 & 223 & 90 \\
\hline
\end{tabular}

Table 3

Female, Three Generational Linkages

\begin{tabular}{|c|c|c|}
\hline Father & Girl & $\begin{array}{c}\text { Paternal } \\
\text { Grandmother }\end{array}$ \\
\hline 68 & 145 & 57 \\
\hline Mother & Girl & $\begin{array}{c}\text { Maternal } \\
\text { Grandmother }\end{array}$ \\
\hline 103 & 225 & 89 \\
\hline
\end{tabular}


and girls who were evaluated for whether they carried the same or different names as their paternal and maternal grandparents of the same sex. ${ }^{6}$

This analysis was inspired by Marshall's (1976) ground-breaking report on the naming customs among Ju/'hoansi. It is important to note that Marshall describes the custom only in normative terms: she states the gender inequality that existed in authority to name children, and implied but did not pursue the topic of probable lateral bias in favor of naming for paternal and non-maternal grandparents.

A man invariably names his first-born son for his father (i.e., the child's $\mathrm{FaFa}$ ) and his first-born daughter for his mother (the child's FaMo).... I believe that the !Kung adhere strictly to this rule. . . A man often, but not invariably, names his second-born son for the child's MoFa and second-born daughter for her MoMo. Subsequent children, I was told, are usually named for the siblings of their father or mother, or for the spouses of those siblings (Marshall 1976:224-25).

Marshall's wording leaves it to the reader's inference that maternal grandparents, being "later in line" for the privilege of being name honoree, might be passed over in favor of other lateral kin. Good data exist on the specifics of each individual's intergenerational linkages among family members from the same time period and from a geographical area adjacent to the one reported by Marshall. These data permit investigating whether Ju/'hoansi followed their own cultural rule about naming, and to determine the extent to which a patrilateral bias was apparent in the naming practices.

\section{FINDINGS}

There are different ways of testing the strength of the patrilateral bias in naming for grandparents. We asked first: "What percentage of men name for the paternal vs. maternal grandparents for any child of the correct sex, regardless of the child's birth order?" Our second question was: "What percentage of men name for the grandparents at the first opportunity, as the naming rule dictates?" Since children are not necessarily born in alternating genders, we could not answer this question by looking solely at children's birth orders. It was necessary to sort children in gender sequence for each father, and to determine whether a given child, though he might have been third-born, could have been the first son and therefore eligible to become the namesake for the father's father. In this way, we coded each child by his or her sequential gender birth order and counted the occurrences of children who were "correctly named at the first opportunity."

The findings for the first question appear in Figure 1. Eighty-one percent of men (58/72) who had at least one son named a boy for a paternal grandfather, and 75 per cent of men (51/68) who had at least one daughter named a girl for 
Figure 1:

Percent of men and women who had a son or daughter named for one of four grandparents

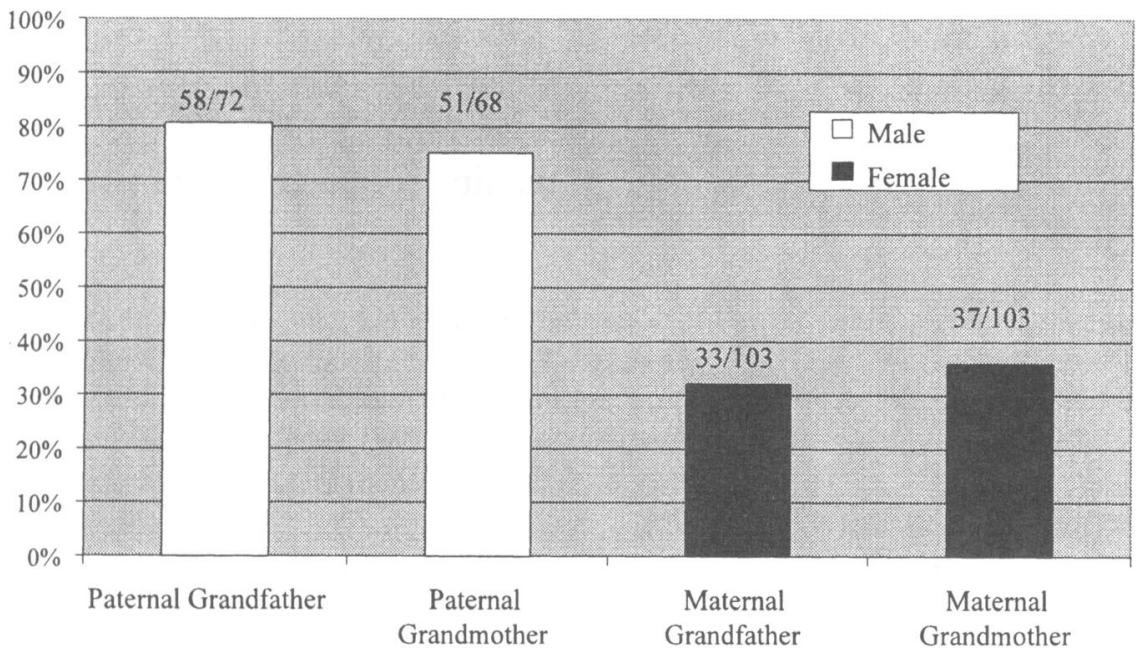

Figure 2:

Percent of men who named a child for a paternal grandparent at first opportunity, later, or never

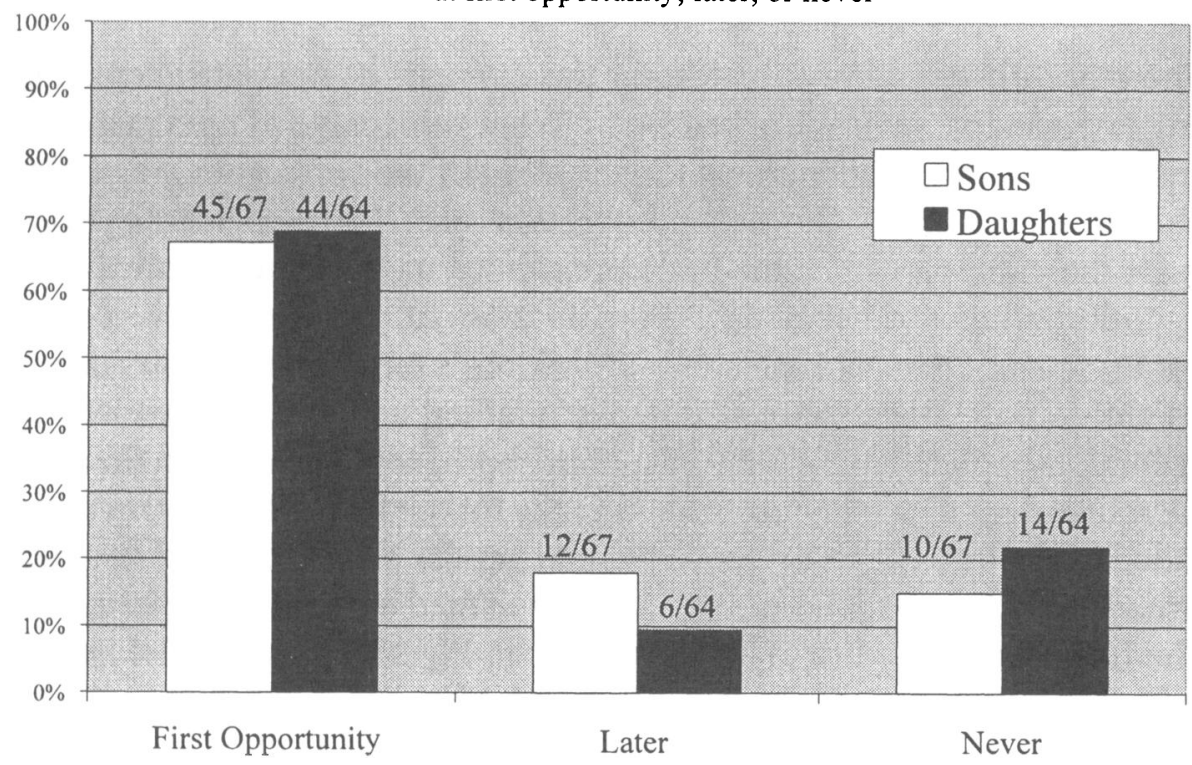


her paternal grandmother. [The $\mathrm{X}^{2}$ test of independence statistic for the values of girls and boys named and not named for their same-sexed paternal grandparents: $\mathrm{X}^{2}(1)=41.279, \mathrm{p}=<.001$.]

Thirty-two percent of women who had a son (33/103) saw their husbands name the son for the maternal grandfather; 36 percent of women $(37 / 103)$ who had a daughter had a namesake for the maternal grandmother. [The $\mathrm{X}^{2}$ test of independence statistic for the values of girls and boys named and not named for their same-sexed maternal grandparents: $X^{2}(1)=13.291, p=<.001$.]

Two effects are apparent and they run in opposite directions for the choices made by men to name for paternal and maternal grandparents. A majority of the men ( 70 percent) named a child for the paternal grandparents. A majority of men (around 70 per cent) did not name for the maternal grandparents. On the other hand, with regard to naming a child for either of the two sets of grandparents, men did not discriminate by the sex of the child. Within grandparent pairs of either the maternal or paternal side, girls and boys were equally likely to be named for a grandparent, though relatively few children of either sex were named for the maternal grandparents. Men were more than twice as likely to award a grandchild namesake on their own parents as on their wife's parents.

For findings on the second question (see Figure 2), the data on the percentages of men naming for their own parents are presented without comparison with the maternal grandparent namesakes. The cases involving maternal grandparents were few and are omitted from this example. The sample size of men and children available for this computation were reduced in comparison with the analyses above because, in a few cases, there were children whose birth orders were not known. Children who had died before being named were also dropped. Figure 2 shows the percentages of men who named a girl or boy for their own parent at their first opportunity, later opportunity, or never.

Sixty-seven per cent of men (45/67) who had at least one son, named the son according to the rule at the first opportunity. Eighteen per cent of men (12/67) who did not name for their own fathers at the first possible time went on to name a later son. Fifteen per cent of men (10/67) who had sons did not name any son for their fathers. Fathers of daughters named first opportunity girls for their own mothers at about the same rate as they named first opportunity sons for their fathers. However, as can be seen in Figure 2, men who did not name their first opportunity girl "correctly" were thereafter less likely to follow the rule for daughters than they were for sons. [The Chi Square test of independence statistic for the values of girls and boys named "first," named "later," and "never named" for their same-sexed paternal grandparents: Chi Square(2) $=41.104, p=<.001$.] 


\section{DISCUSSION}

The naming rule described by Marshall is that men, not women, have the authority to name their children, and that their first obligation is to name for the paternal grandparents and later for the wife's parents or other relatives who are a generation older than the child. Marshall's description was about the rules of the custom and not about the actual empirical conformity to the rule. Our analysis of data, collected at about the same time as the ethnographic present of Marshall's ethnography on a neighboring Ju/'hoan population, demonstrates that $\mathrm{Ju} /$ 'hoansi of the Dobe area, Botswana, follow their own rules at the rate of slightly under 70 per cent, if the test is naming for the fathers' parents at the first opportunity of a child of the appropriate sex. (Figure 2).

If a more liberal interpretation of the rule is used, men conform at a rate of 80 per cent and 75 per cent to the naming custom by naming some child for the paternal grandfathers and grandmothers, respectively, regardless of gender sequence (Figure 1). In comparison, men name their children for their wives' parents at a much lower rate, around 35 per cent. Clearly, contra Marshall, the $\mathrm{Ju} /$ 'hoan men of the Dobe area did not invariably name the first-born girl and first-born boy "correctly." In Figure 2, the data show that 33 per cent of the sample (22/67) men failed to name a first-born son (first opportunity) for the paternal grandfather, and 31 per cent (20/64) failed to name a first-born daughter for the paternal grandmother.

We speculate that the gender sequence of men in their own sibships may account for some of this variability. For example, men who were first-born males among their siblings would have been, on average, more likely to have had living parents at the time their own children were born, in comparison with their younger brothers. It is conceivable that a man would have been more likely to confer a namesake on his father during the father's life, rather than posthumously. Undoubtedly, some of the 72 men were later-born sons. Perhaps the elder brothers had already conferred namesakes on the father or mother, leading the younger brother to choose other relatives as name honorees. Unfortunately, the particular components of the Harvard Kalahari Research Project data are not complete regarding the birth orders of the adult men; therefor, we could not identify a sufficiently large sample to answer this question. Draper collected genealogical and demographic intergenerational data on Ju/'hoansi of the Dobe area approximately twenty years later. She interviewed adults about their own offspring as well as about the offspring of their parents. The data from the later time will support such an analysis of the sibling order of parents of children and will be reported in a forthcoming publication. ${ }^{7}$

How can these apparent differences in conformity to the naming rule be interpreted? Because Marshall did not report, as we have, a statistical average of 
compliance with the norm to name for grandparents, we do not know what level of conformity actually existed among the Nyae Nyae Ju/'hoansi at the time of her study nor, therefore, how similar or dissimilar the Dobe and Nyae Nyae $\mathrm{Ju} /$ hoansi may have been in upholding the naming custom. Further, as Marshall carefully states in connection with dead children of her study, "My genealogical records are not full enough with respect to the dead for me to trace every naming" (Marshall 1976:225). In comparison, the demographic data on the reproductive histories of the $1968 \mathrm{Dobe} \mathrm{Ju} /$ 'hoansi are based on detailed and cross-checked interviewing by Howell and Lee. For Dobe area Ju, we can report a robust preference for naming for the father's parents but compliance is well short of 100 per cent.

Patrilateral bias in the domain of naming is unarguably present among the $\mathrm{Ju} /$ 'hoansi and constitutes an exception to an otherwise gender egalitarian and nonunilateral bias in Ju/'hoan customs. But what significance may it have had elsewhere in $\mathrm{Ju} /$ 'hoan social life? In order to formulate this answer we need to elaborate on the features of the naming custom. As Marshall (1957) explained, the Ju/'hoansi use the "name sameness" as a basis for extending fictive kin relationships. This "homonymic" principle, as she termed it, applies to the old name/small name relationship. The small name can acquire his or her grandparent namesake's social network because numerous other people, older than the child, and who knew the old name from times past, refer to the child by the same kin terms they used for the old name. An adjustment was made in recognition of the fact that the child was younger than the old name's acquaintances $^{8}$

The homonymic principle for the extension of fictive kin relations applies to anyone who wished to incorporate a technical stranger into his or her kin terminological system. The leveraging of name relationships was an extremely important concrete as well as symbolic feature of Ju/'hoan social life. It has been discussed by Marshall (apropos of the 1950s) and in general terms by Lee, who also provided details on the frequency of male and female personal names for a time period (1960s) comparable to the one we have addressed in this article (Lee 1986:87-9). Both Marshall and Lee elaborate on how Ju/hoansi used the name homonymic feature as a social passport (Lee 1979:13). When people visited in a distant region where they did not have close genealogical connections that allowed them to ally themselves on the basis of kinship, they could rely on the personal name to ease their entrée to new social situations. The following illustration may help visualize how the custom worked.

Consider a fictive woman, "Bau," who was a stranger to all the people in a community she visited. Lacking direct genealogical relationship with anyone, she could be incorporated into the kin networks of people on the basis of her name. Bau would be told by a person, "My sister is Bau, so you and I will be sisters." 
In due process, other members of the group Bau was visiting would work her in to their own kin systems on the basis of her name and its similarity to others they knew, also called Bau. Bau became mother to some, and sister-in-law, grandchild, niece, and even "wife" to others. The older person had the privilege vis-à-vis Bau of deciding what kin relationship he or she had with one or perhaps several other "Baus" in order to invoke a specific relationship with our hypothetical "Bau." All these relationships, although fictive, were governed by the avoidance or joking components of the relationships that obtained between the other person and the "Bau" whose name was used in the name homonymic way.

Given that Marshall had explained the naming rule in terms of the father's right to name children and the patrilateral over matrilateral precedence in assigning namesakes for grandparents, we expected to find more fathers' parents as old names to grandchildren than mothers' parents. As noted before, men had the option but not the obligation to name later-born girls and boys for the wife's parents. We were surprised that overall compliance to the naming rule (around 75 to 80 per cent) for father's parents was not higher, since the naming custom was originally described in rather inflexible terms. Further, we did not expect to find the low frequency of naming for maternal grandparents. Only about 30 per cent of men named for their wives' parents in comparison with over twice that rate for their own parents.

On the other hand, perhaps roughly 70 per cent compliance with a cultural rule represents a high level of cultural conformity. In the absence of comparable data from the group studied by Marshall, we do not know what to make of the apparent discrepancy with her implied 100 per cent compliance.

Does knowing the actual, empirical, imbalance in naming for the paternal and not the maternal side give new insight into gender relations, previously understood to be highly egalitarian? Perhaps the gender inequality in naming for paternal vs. maternal side was, at the time of data collection, effectively neutral in terms of material consequences since, as pointed out above, there were many compensating features of gender equality that were instantiated in the social structure in the $1960 \mathrm{~s}^{9}{ }^{9}$ The cultural data available permit only a crude tally of the frequencies of shared names among grandparents and grandchildren. Since we pose questions about the naming custom and the degree of its compliance long after the decisions were made by the actual actors, we cannot calculate what wider import the patrilateral bias in naming for the paternal side may have had on family or gender relations. The fact that men varied among themselves in following the rule (some never named a child correctly, and some failed to name the first-born of either gender correctly) suggests that some strategy may have guided the choice of old name for the babies. Regrettably, neither Draper nor 
other ethnographers of that era collected systematic interviews with $\mathrm{Ju} /$ 'hoan parents of newborns about who would or would not be the old name.

Perhaps the patrilateral bias is an example of what Kluckhohn(1943) referred to as "covert culture," meaning "a sector of culture of which members of the society are unaware or minimally aware" (Kluckhohn 1943:217). Ju/'hoansi, of course, were aware of the rule of naming but may have had no appreciation of its possible psychological ramifications. In this light we suggest that the naming choices for the first girl and first boy born to each married couple may have precipitated a strong signal of connectivity to the father's mother and father, and to their social networks, on behalf of the child. As we have described above, the name of the child and its correspondence to a grandparent's name was only the initial component in a widely ramifying network of possible connections that other people could invoke on behalf of the old name. The naming choices men made for their first two or three children may have subtly or overtly encouraged more frequent social ties with the patrilateral kindred, in comparison with the matrilateral kindred. ${ }^{10}$

Recall that some children, especially those born later to their parents, were named for other kin who could be relatives or in-laws of either the mother or father. We know of no reports of any biases - kin lateral, territorial, or otherwise - that may have influenced the fathers' choices of names for later-born boys and girls. Such an investigation, even in recent times when the naming custom is still followed, could reveal important insights into the possible social strategies that fathers employ for themselves and their children.

Anthropologists have been concerned with the concepts of culture and, more specifically, the content of culture in the form of institutions and norms since the beginnings of the discipline. As the discipline matured, more attention has been paid in some sectors to the behavioral dimension of culture (Barth 1967; Borgerhoff Mulder, and Caro 1985; Goodenough 1956; Mitchell 1967). This development has inevitably given rise to questions about the relationship between norms, values, and other ideational aspects of culture and the actual behavior of people whose minds and actions are presumably governed by the internalized prescriptions and information content of culture (Boster 1986; Romney, Weller, and Batchelder 1986). Do people think alike and do what they are supposed to do? Who does? Who doesn't? What is the meaning of nonconformity to cultural rules in particular cases (D'andrade 1984; Ensminger and Knight 1997)?

The exercise undertaken in this article is in this tradition. It goes without saying that answering such questions requires quantifiable data about cultural practice as well as the equally important and essential contextual knowledge about the motivations of interviewees. In our case, by analyzing the correspondence in names of grandparents and grandchildren, we have opened 
only a small door into the important and pervasive custom of naming and name relationships among the Ju/'hoansi. According to modern informants, both $\mathrm{Ju} /$ 'hoansi and Euro-Americans, the naming customs continue to be practiced among the Ju of Botswana and Namibia. We hope that the empirical patterns we have uncovered and the questions we have raised will lead others to explore these issues in the ethnographic present in which local cultural actors can be asked to account for the choices they make in conferring names on their children.

\section{NOTES}

1. The repertoire of names as well as their rank order in frequencies varied regionally. The correspondence in both male and female name frequencies is very close for the Ju/'hoansi of the Dobe area when comparing population data gathered in 1968 and in 1988. This indicates cultural stability in the naming custom despite marked change in other sectors of culture, such as subsistence economy and reduced residential mobility.

2. These researchers were supported by grant MH-12611 from the National Institute of Mental Health to Irven DeVore and Richard Lee, Co-principal Investigators, 1967-1972. Draper's later research was supported by the National Institute of Aging, Grant No. AG03110, Co-Principal Investigators: Christine Fry and Jennie Keith

3. Nancy Howell made available the codes and data from her interviews with $165 \mathrm{Ju}$ women. These materials have been archived at the University of Toronto Library. Also available from the Toronto Archives was the numbered listing of the names and ages of the approximately 800 individuals originally given identifying numbers by Richard Lee.

4. The original listing of 800 or more people was increased substantially by Draper, who added individual records on people omitted from the original listing. For example, Ju who were alive but not personally observed by Lee or people who were dead at the time of data collection in 1967-69 were not given identifying numbers. However, since these people were the grandparents, siblings, non-Ju/'hoan fathers, or offspring of the original 800 people, it was essential to include records on them in order to calculate intergenerational relationships. The final database, called the Ju/'hoan Data Compendium 1967-69 (JDC), contained over 1600 records.

5. For example, we included some but not all of the 165 women originally interviewed by Howell, the children of those women, and the men who fathered the children. Also included were men and women of the / $\mathrm{Du} / \mathrm{da}$ area whose reproductive histories and genealogical relations were collected by Draper in 1968-69.

6. These tables can be read as follows: There were 72 men who had 152 sons whose names were compared with the names of their 61 grandfathers. There were 68 men who had 145 daughters, whose names were compared with the names of 57 grandmothers. Most of these men and women had two or more children who, together with the children's grandparents, are enumerated. The analyses are expressed in terms of the percentages of men and women whose daughter or son was named for either the paternal or maternal grandparent. Although it is men who actually confer names, in order to determine whether children were named for the maternal grandparents it was necessary to know the identity of the wives of men, and the names of the wives' parents, in order to calculate whether a man's children by a particular woman were named for the maternal grandparents. Therefore, the last two lines of Table 2 can be read: there were 103 women who had 223 boys, accounted for by 90 maternal grandfathers. In Table 3 there were 103 women who had 225 girls, accounted for by 89 maternal grandmothers. It will be apparent that the total number of children in this table exceeds the total number of discrete children (480) in the actual sample. The reason is that many but not all of the children are common to the parents 
and therefore may be enumerated twice: once for their father and their same-sexed paternal grandparent, and once for their mother and their same-sexed maternal grandparent.

7. Several articles have been published using Draper's data from the late 1980s on kinship, intergenerational relations, and reproductive histories of Ju/'hoansi of the Dobe area. (Draper and Hames 2000; Draper and Howell 2005; Draper and Keith 1992; Draper and Kranichfeld 1990). 8. For example, if the person previously known to the child's grandparent called the old name "uncle," and was in turn addressed by the grandparent as "niece" or "nephew" (depending on gender), then he, being older than the grandchild small name, reversed the seniority inherent in the uncle/aunt vs. niece/nephew kin terms. When the other person addressed the small name, she or he called the child by the niece/nephew term, and the child addressed the other as aunt/uncle. 9. Thanks go to Willow Powers for raising this point.

10. Male and female cousins, united by their fathers who were brothers, would also include children named for the same paternal grandparents. Whether these cousins who shared a common old name came, over time, to recognize any special solidarity in sentiment or action, over and above that of recognizing common grandparents, is not known.

\section{Bibliography}

Barth, F. 1967. On the Study of Social Change. American Anthropologist 69:661-69.

Becker, H. 2003. The Least Sexist Society? Perspectives on Gender, Change and Violence among Southern African San. Journal of Southern African Studies 29(1):5-23.

Borgerhoff Mulder, M., and T. M. Caro. 1985. The Use of Quantitative Observational Techniques in Anthropology. Current Anthropology 26(3):323-34.

Boster, J. S. 1986. Requiem for the Omniscient Informant: There's Life in the Old Girl Yet. Directions in Cognitive Anthropology, ed. J. W. Dougherty, pp. 177-97. Urbana.

D'Andrade, R. G. 1984. Cultural Meaning Systems. Culture Theory: Essays on Mind, Self, and Emotion, eds. R. A. Shweder, and R. A. LeVine., pp. 88-119. Cambridge.

Draper, P. 1975. !Kung Women: Contrasts in Sexual Egalitarianism in the Foraging and Sedentary Contexts. Toward an Anthropology of Women, ed. R. R. Reiter, pp. 77-109. New York.

1992. Room to Maneuver: !Kung Women Cope with Men. Sanctions, and Sanctuary: Cultural Perspectives on the Beating of Wives, eds. D. A. Counts, J. K. Brown, and J. C. Campbell, pp. 43-61. Boulder.

Draper, P., and R. Hames. 2000. Birth Order, Sibling Investment, and Fertility among the Ju/'hoansi (!Kung). Human Nature 11(2):117-56.

Draper, P., and N. Howell. 2005. The Growth and Kinship Resources of !Kung Children. HunterGatherer Children, eds. B. Hewlett and M. Lamb, pp. 262-81. New Brunswick.

Draper, P., and J. Keith. 1992. Cultural Contexts of Care: Family Caregiving for Elderly in America and Africa. Journal of Aging Studies 6(2):113-33.

Draper, P., and M. Kranichfeld. 1990. Coming in from the Bush: Settled Life by the !Kung and Their Accommodation to Bantu Neighbors. Human Ecology 18(4):363-84.

Ensminger, J., and J. Knight. 1997. Changing Social Norms: Common Property, Bridewealth, and Clan Exogamy. Current Anthropology 38(1):1-24.

Goodenough, W. H. 1956. Residence Rules. Southwestern Journal of Anthropology 12:22-37. Haney, C. E. 2004. Naming Practices among the Ju/hoansi San: Analyzing a Cultural Ideal. Master's Thesis. University of Nebraska.

Hays, J. 2003. Rethinking Education for All: Matching Global Rhetoric with Local Reality. Gaborone. 
Hitchcock, R. K., M. Johnson, and C. E. Haney. 2005. Indigenous Women in Botswana: Changing Gender Roles in the Face of Dispossession and Modernization. Indigenous People's Rights in Southern Africa, eds. R. Hitchcock and D. Vinding, pp. 166-82. Copenhagen.

Howell, N. 2000a. Bushmen Demography: Demography of the Dobe !Kung 1963-1973. University of Toronto: Data Library Service.

2000b. Demography of the Dobe !Kung. New York.

Kluckhohn, C. 1943. Covert Culture and Administrative Problems. American Anthropologist 45:213-27.

Lee, R. B. 1965. Subsistence Ecology of !Kung Bushmen. Ph. D. dissertation, University of California.

1969. Eating Christmas in the Kalahari. Natural History (December):14-22, 60-63.

1974. Male-Female Residence Arrangements and Political Power in Human Huntergatherers. Archives of Sexual Behavior 3(2):167-73.

1979. The !Kung San: Men, Women, and Work. Cambridge.

1986. !Kung Kin Terms, the Name Relationship, and the Process of Discovery. The Past and Future of !Kung Ethnography: Critical Reflections and Symbolic Perspectives. Essays in Honor of Lorna Marshall, eds. M. Biesele, R. Gordon, and R. Lee, pp. 103-36. Hamburg.

Lee, R. B., and R. K. Hitchcock. 2001. African Hunter-gatherers: Survival, History, and the Politics of Identity. African Study Monographs Supplement 26:257-80.

Lee, R. B., and S. Hurlich. 1982. From Foragers to Fighters: South Africa's Militarization of the Namibian San. Politics and History in Band Societies, eds. E. Leacock and R. B. Lee, pp. 327-45. Cambridge.

Marshall, L. 1957. The Kin Terminology System of the !Kung Bushmen. Africa 27:1-25.

1959. Marriage among the !Kung Bushmen. Africa 29:335-65.

1961. Sharing, Talking, and Giving: Relief of Social Tensions among the !Kung Bushmen. Africa 31(3):231-49.

1976. The !Kung of Nyae Nyae. Cambridge.

Mitchell, J. C. 1967. On Quantification in Social Anthropology. The Craft of Social Anthropology, ed. A. L. Epstein, pp. 17-45. London.

Ritchie, C. 1986. From Foragers to Farmers: The Ju/wasi of Nyae Nyae Thirty Years On. The Past and Future of !Kung Ethnography: Critical Reflections and Symbolic Perspectives. Essays in Honor of Lorna Marshall, eds. M. Biesele, R. Gordon, and R. Lee, pp. 311-27. Hamburg.

Romney, A. K., S. C. Weller, and W. H. Batchelder. 1986. Culture as Consensus: A Theory of Culture and Informant Accuracy. American Anthropologist 88:313-38.

Saugestad, S. 2003. What Has Changed? 1993-2003. Gaborone.

Sylvain, R 2004. San Women Today: Inequality and Dependency in a Post-foraging World. Indigenous Affairs 1-2(4):8-13.

In press. Drinking, Fighting, and Healing: San Struggles for Survival and Solidarity in the Omaheke Region, Namibia. Updating the San: Image and Reality of an African People in the $21^{\text {st }}$ Century, eds. R. K. Hitchcock, E. Kazunobu, R. B. Lee, and M. Biesele.

Wiessner, P. 1982. Risk, Reciprocity, and Social Influences on !Kung San Economics. Politics and History in Band Societies, eds. E. Leacock and R. Lee, pp. 61-84. Cambridge. 2002. Taking the Risk out of Risky Transactions. Risky Transactions: Trust, Kinship, and Ethnicity, ed. F. K. Salter, pp. 21-43. New York. 
2004. Owners of the Future? Calories, Cash, Casualties, and Self Sufficiency in the Nyae Nyae Area between 1998 and 2003. Visual Anthropology 19(1-2):149-59.

Yellen, J. E. 1990. The Transformation of the Kalahari !Kung. Scientific American (April):96-105. 